\title{
Does Virtual Reality Affect Children's Dental Anxiety, Pain, And Behaviour? A Randomised, Placebo-Controlled, Cross-Over Trial
}

${ }^{1}$ Department of Pediatric Dentistry, Faculty of Dentistry, Sivas Cumhuriyet University, Sivas, Turkey.

Correspondence: Associate Professor Burak Buldur, DDS, Ph.D., Department of Pediatric Dentistry, Faculty of Dentistry, Cumhuriyet University, Kampus, 58140, Sivas, Turkey. E-mail: bbuldur@gmail.com

Academic Editor: Lucianne Cople Maia

Received: 29 April 2020 / Review: 21 July 2020 / Accepted: 07 September 2020

How to cite: Buldur B, Candan M. Does virtual reality affect children's dental anxiety, pain, and behaviour? A randomised, placebo-controlled, cross-over trial. Pesqui Bras Odontopediatria Clín Integr. 2021; 21:e0082. https://doi.org/10.1590/pboci.202 1.002

\begin{abstract}
Objective: To evaluate the effect of virtual reality (VR) on dental anxiety, pain, and behaviour at different time points among children undergoing dental treatment under local anaesthesia. Material and Methods: This randomised, two-armed, within-subject, cross-over, placebo-controlled trial included 76 children. Eligible participants were treated in two dental visits using the following methods: with protective glasses only, without distraction (attention placebo-controlled - APC); and with the treatment condition (i.e., VR). Primary outcomes were dental anxiety and pain; secondary outcome was dental visit behaviour. Heart rate scores were recorded as an objective measure to evaluate dental anxiety and pain. Subjective measurements for each variable were also performed. Results: Significant reduction in dental pain and anxiety was observed in the VR group, according to the heart rate scores; however, no statistical differences were observed according to the self-reported measures. Decreased dental anxiety and pain were associated with the first visit sequence with VR. Dental pain and anxiety scores were lower during local anaesthesia in the VR group than in the APC group. Conclusion: Virtual reality significantly reduced pain and anxiety during local anaesthesia in children undergoing dental treatment; therefore, it may be recommended during dental treatment in school-age children.
\end{abstract}

Keywords: Behavior Observation Techniques; Dental Anxiety; Toothache; Virtual Reality. 


\section{Introduction}

Dental anxiety has become a leading health problem throughout the world, both among children and adults [1-3]. Patients with dental anxiety avoid common dental treatment procedures and equipment such as extractions, drills, and needles [4,5]. Dental anxiety is also associated with both state anxiety and pain experienced during dental procedures [6].

Routine distraction techniques are widely used for behaviour management in paediatric dentistry because they are simple, safe, and inexpensive [7-9]. These techniques aim to distract children from painful and unpleasant stimuli by means of television (TV), music, and/or storytelling [8,10-12]. However, watching $\mathrm{TV}$ or listening to music during dental treatment to reduce pain and anxiety would only be effective if the child's attention is completely focused on the TV, thereby distracting him/her from the surrounding environment [13].

Exposure-based treatment programs are considered to be the gold standard for managing specific fears and phobias, including those related to dental treatment situations [14,15]. Virtual reality (VR) is increasingly used in the treatment of patients with specific phobia(s), and is frequently used in many medical fields, including medicine and dentistry [15]. A meta-analysis reported that VR has large effect sizes relative to controls and may be more appealing to patients, thus making it easier to tolerate anxiety- and painprovoking procedures [15]. VR may help in distracting patients from fears provoked by objects and situations in a well-controlled, computer-generated virtual environment until the disappearance of their fears and anxieties [16]. The VR intervention should be designed in a manner that contravenes expectations and should be applied until the factors that cause the fear(s) have passed [15]. For VR to be effective and interesting for patients, the virtual environment must evoke a sense of being present and of reality during therapy [14].

VR has some advantages over current non-pharmacological behaviour guidance techniques [17-21]. VR is a safe technique because patients meet the virtual representation of the threat in a more gradual and controlled manner [22]. Because the entire exposure process in VR is completed in the privacy of the dental office, it may create less fear of social embarrassment for patients [23]. VR may be repeated as necessary, without any additional cost [15]. Techniques, such as cognitive behavioural therapy or in vivo exposure therapy, require specialised training for therapists and are usually delivered by trained psychologists [24]. Conversely, the implementation of VR may require only a working knowledge of computers and basic training to operate the device [19]. VR is also associated with better patient acceptance compared with routine nonpharmacological behaviour management techniques in dentistry [25].

Although VR has many advantages in the fields of dentistry and medicine [7,8,11,15,17,21,25-29], limited research attention has been devoted to the investigation of the effectiveness of VR in reducing anxiety and pain during dental treatment in children. There is also a lack of VR use in randomised, controlled, clinical trials in dentistry. In addition, the potential of the 'Hawthorne effect' [30] - in which the subjects participating in the research are aware that they are selected for the experiment, and in this case, the researcher expects positive behavioural changes from them - has been ignored in virtually all previous clinical trials that have assessed the utility of VR using subjective measurement tools by the participants [21]. Attention placebocontrolled (APC) groups are therefore used to address non-specific effects that may be imparted when clinicians or study investigators devote attention to subjects [31]. To our knowledge, no studies have used an APC group in a randomised clinical trial evaluating dental anxiety and pain; however, such a group should be used in these trials to control the possible impact of the Hawthorne effect. Although cross-over study desing 
enables to reduce the influence of confounding covariates because each cross-over patient serves as their own control, there has been given little research attention on cross-over studies in pediatric dental practice.

Considering the above rationales, this study aimed to evaluate the effect of VR on dental anxiety, pain, and behaviour at different time points among children undergoing dental treatment under local anaesthesia. The null hypotheses were as follows: VR has no effect on reducing dental anxiety and dental pain scores of participants, and there is no difference between subjective and objective measure scores of dental anxiety and pain when VR and APC modalities are used to reduce anxiety in children undergoing dental treatment with local anaesthesia.

\section{Material and Methods}

\section{Selection Criteria}

This randomised, two-armed, placebo-controlled, cross-over, clinical trial adhered to the principles of the Declaration of Helsinki, good clinical practice guidelines, and applicable regulatory requirements. Ethical approval was obtained from the Local Health Ethics Committee. All parents or guardians of the patients were educated about the study before enrolment and provided informed written consent to participate. The trial adhered to the Consolidated Standards of Reporting Trials (CONSORT) guidelines. The study has been registered in ClinicalTrials.org (ID NCT04226651).

The parameters used to calculate the sample size included a 95\% confidence interval (CI), $80 \%$ statistical power, and a standard deviation of 1.90 [27]; accordingly, at least 64 subjects were required. This number was adjusted to 76 subjects to compensate for a projected loss of approximately $20 \%$ during follow-up. Thus, 76 healthy subjects between 7 and 11 years of age were included in the study. Participants who fulfilled the following criteria were included: systemically and mentally healthy; requiring restorative treatment for the first mandibular permanent molar tooth with occlusal dentine caries in each mandibular quadrant with a bilateral inferior alveolar nerve block; absence of co-operative disability; and Frankl Scale score of 2 or 3 [32] during first dental examination. Patients with systemic or mental illnesses, reduced audiovisual capabilities, acute dental pain or trauma, previous painful or negative dental experience, and who were extremely uncooperative were excluded.

\section{Study Design}

The present randomised, two-armed, within-subject, cross-over, placebo-controlled trial included patients who applied to the Department of Paediatric Dentistry for routine dental treatment. The CONSORT flow diagram illustrating the trial design and protocol is presented in Figure 1.

The study comprised three visits: Vo, baseline dental examination and inclusion; V1, first restorative treatment session; and V2, second restorative treatment session for same tooth in the opposite quadrant. The initial oral and radiographic examination and Frankl Behaviour Scale scoring of all patients were performed by one experienced and pre-calibrated researcher. A dental assistant not participating in the study used a randomorder generator (http://www.random.org) to randomise patients to the experimental group according to block randomisation. Baseline participant characteristics are summarised in Table 1. There were no significant differences among participants in terms of age, sex, or dental anxiety scores. 


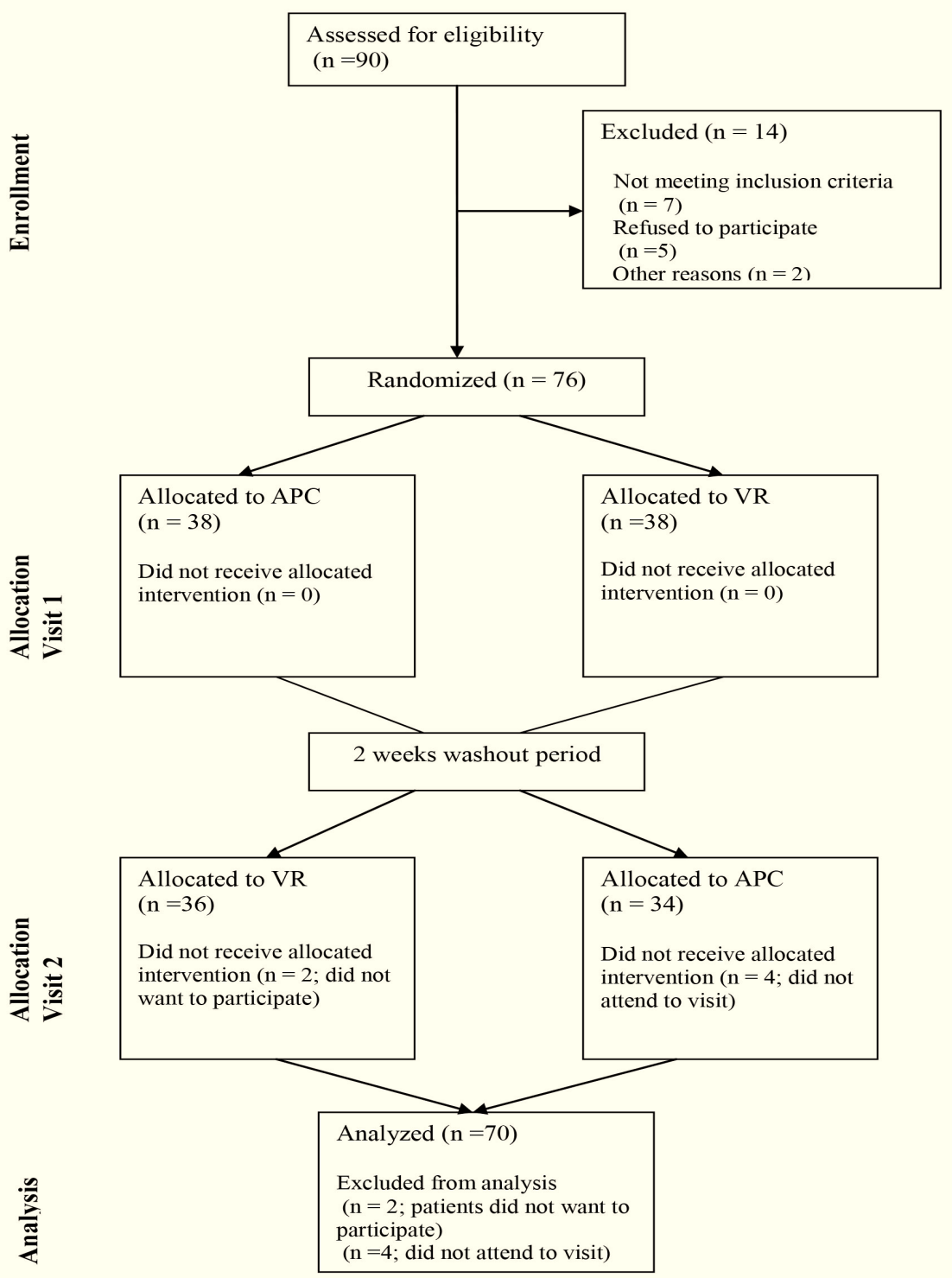

Figure 1. CONSORT flow diagram.

Table 1. Baseline characteristics of participants according to treatment groups

\begin{tabular}{|c|c|c|c|c|c|c|}
\hline \multirow[t]{2}{*}{ Variables } & \multicolumn{2}{|c|}{ Group A - APC } & \multicolumn{2}{|c|}{ Group B - VR } & \multicolumn{2}{|c|}{ Total } \\
\hline & $\mathrm{N}$ & $\%$ & $\mathrm{~N}$ & $\%$ & $\mathrm{~N}$ & $\%$ \\
\hline Subjects & 38 & 50.0 & 38 & 50.0 & 76 & 100 \\
\hline \multicolumn{7}{|l|}{ Sex } \\
\hline Female & 18 & 47.4 & 19 & 50.0 & 37 & 48.7 \\
\hline Male & 20 & 52.6 & 19 & 50.0 & 39 & 51.3 \\
\hline \multicolumn{7}{|l|}{ Age } \\
\hline Mean \pm SD & \multicolumn{2}{|c|}{$8.97 \pm 1.38$} & \multicolumn{2}{|c|}{$9.07 \pm 1.42$} & \multicolumn{2}{|c|}{$9.02 \pm 1.39$} \\
\hline 7 Years & 7 & 18.4 & 7 & 18.4 & 14 & 18.4 \\
\hline 8 Years & 8 & 21.1 & 7 & 18.4 & 15 & 19.7 \\
\hline 9 Years & 9 & 23.7 & 8 & 21.1 & 17 & 22.3 \\
\hline 10 Years & 7 & 18.4 & 8 & 21.1 & 15 & 19.7 \\
\hline 11 Years & 7 & 18.4 & 8 & 21.1 & 15 & 19.7 \\
\hline \multicolumn{7}{|l|}{ Baseline Anxiety Scores } \\
\hline Mean \pm SD & \multicolumn{2}{|c|}{$37.38 \pm 4.78$} & \multicolumn{2}{|c|}{$37.67 \pm 7.98$} & \multicolumn{2}{|c|}{$37.52 \pm 6.48$} \\
\hline Minimum-Maximum & 30 & 59 & 32 & 68 & 30 & 68 \\
\hline
\end{tabular}

*APC: Attention Placebo-Controlled; VR: Virtual Reality; SD: Standard Deviation. 


\section{Pilot Study}

A pilot study was performed with 20 children (mean age, $8.24 \pm 1.26$ years) to test the compatibility and acceptability of the VR headset. All children were asked to wear the VR headset along with or without watching a movie. This measure was an attempt to control bias by permitting subjects to wear the VR headset without playing any movies. However, most children $(n=14 ; 70 \%)$ refused to wear the VR headset without a movie during treatment. They cited fear of losing control over the dental procedure as the reason for the refusal to wear the VR headset. Thus, routine protective glasses were provided and were found to be acceptable to all children. Findings from the pilot study confirmed the applicability of the study design and protocol.

Eligible participants were treated in two different appointments using the following two modalities: using protective glasses only, without distraction (APC); or with the treatment condition (VR). All procedures were performed by a single experienced and calibrated paediatric dentist.

Participants were randomly assigned by a computer algorithm to receive VR with the first or second sequential dental treatment session and with protective glasses for the other treatment session. The investigators were blinded to treatment sequence until before the onset of the first dental treatment. Before VR, the VR headset was shown to the patients, who were permitted to handle it. This enabled the patient to recognise the device and be familiar with it before treatment. Before starting the treatment, the VR headset was placed on each patient's head, and the patient was asked whether the device caused pain or discomfort, and the patient's consent was confirmed. In the APC group, each patient was informed about the dental procedure and was provided with protective glasses. All patients were told that they were wearing these glasses to ensure a pain- and stress-free treatment, and that the dentist would devote additional attention to the treatment. This aimed to provide the patient with a feeling similar to being in an experimental session. The reason for choosing an APC group with the routine protective glasses without distraction was to mitigate the possibility of the 'Hawthorne effect' [30]. One important factor to eliminate in experimental designs is the 'Hawthorne effect', in which the study subjects are aware that they have been selected for an experiment and, such as in this case, the researcher expects positive behavioural changes from them. Therefore, the use of an APC group increases the possibility of associating the findings with only the effect of the treatment [31].

\section{Study Protocol}

\section{VR System}

The VR system (PlayStation 4 VR, Sony Inc., Minato, Tokyo, Japan) is a simple and easy-to-use distraction device. This system consists of a screen mounted on a binocular headset connected to a console or personal computer. The head-mounted display provides a high-resolution visual display and unmutes the sound from the headphones using a soundproof mechanism that provides clear sound. The console or computer is used to create virtual environments, which, in this study, were non-violent and harmless. Participants were asked to watch cartoons or animated films of their own choice. All participants confirmed that the VR headset was not unduly heavy or caused other physical problems. Both investigators were trained in the proper use of the VR equipment and study procedures. The investigator who performed the dental procedures also confirmed that he did not experience any problems during any of the procedures. All procedures were performed in a single room separated for patients.

Dental Treatment Procedure 
Regardless of the experimental group, the first treatment session involved restoring the mandibular first permanent molar tooth with only occlusal dental caries of each patient with composite filling under local anaesthesia, whereas the second session involved treating the same tooth in the opposite quadrant. The duration of treatment in each session was noted and was defined as the time from when the subject sat on the chair until the occlusal adjustment of restoration. First, the teeth were cleaned using fluoride-free prophylactic paste. The cavity preparation was limited to removal of the caries, followed by rounding of the inner line and point angles. The total caries removal was performed on the lateral walls of the cavity with low-speed round burs (sizes 4, 5, and 6, KG Sorensen, São Paulo, Brazil). Selective caries removal was executed on pulpal wall with hand excavators until firm dentin, following it was possible to observe that the remaining dentin had a darker color and leathery consistency. Rounding of the inner line and point angles were performed using an 80 $\mu \mathrm{m}$ grit diamond bur and completed using a $25 \mu \mathrm{m}$ grit diamond bur (Intensiv, Viganello-Lugano, Switzerland). Isolation and contamination were controlled with suction and cotton rolls. Metal matrix bands and wooden wedges were also used where necessary. Teeth were restored with a hybrid composite (Filtek Z250, 3M ESPE) using incremental technique.

\section{Measures}

Before data collection, the investigators were trained in the proper use of the VR equipment and study procedures. Two investigators were present at each treatment session, one of who managed the dental treatment while the other recorded the measurements.

\section{Primary Outcome}

The outcome measures were obtained through objective measurement, heart rate score, and selfadministered questionnaires. Heart rate is a direct measure of physiological action and changes in painful and stressful situations [33]. As reported in previous studies [29, 34], it can be used as an index for evaluating both anxiety and pain. Therefore, it was used as an objective measure for evaluating both dental anxiety and pain in this study. The heart rate score was noted using a portable pulse oximetry device (Shenzhen Jumper Medical Equipment Co., Ltd., Guangong, China), which was attached to the left index finger of each subject.

\section{Dental Anxiety}

Dental anxiety was assessed using the Children's Fear Survey Schedule-Dental Subscale (CFSS-DS) and Facial Image Scale (FIS). After providing informed consent, participants completed a baseline questionnaire (i.e., Vo) in the waiting area of the clinic for providing demographic information and ratings of preoperative anxiety according to the CFSS-DS and FIS. Both of these self-administered measures were also used to evaluate dental anxiety at the end of the first (i.e., V1) and the second dental treatment visits (i.e., V2). The CFSS-DS consists of 15 questions addressing dental treatment and equipment. The answer to each question is scored from 1 (I'm not afraid) to 5 (I'm scared). Anxiety scores ranged from 15 to 75 , with scores classified as follows: 15-31, low level; 32-38, moderate level; and $\geq 39$, high level. The validity and reliability of the Turkish version of the CFSS-DS have been established [35]. The FIS comprises a series of five pictures showing very happy $($ score $=1)$ to very unhappy (score $=5$ ) faces [36]. The scale was shown to the children, who were asked to choose the image they identified with at that instant. The scores were recorded by assigning a score to the chosen face. 


\section{Secondary Outcomes}

Dental Pain

Pain outcome measures were obtained through objective measurement, heart rate score, a selfadministered questionnaire, and the Wong-Bakers Faces Pain Scale (WBS). The WBS consists of six faces that are assigned a rating from 0 to 10 , with 0 representing no pain and 10, the most intense pain. Each face is labelled with short verbal descriptions ranging from 'no hurt' to 'hurts worst'.

The objective measure evaluating pain level was the recorded heart rate. Heart rate scores were recorded four times during each visit session: a minute after sitting in the dental unit (To); before local anaesthesia (T1); during local anaesthesia (T2); and at the end of the treatment (T3). The highest scores were recorded at each time point.

The WBS was used to subjectively measure pain levels and was rated by study participants immediately after local anaesthesia administration (T2) and at the end of the treatment (T3).

\section{Dental Visit Behaviour}

Another secondary outcome measure was the dental visit behaviour of patients. The pre-calibrated investigators scored patient behaviour using the Frankl Behaviour Scale at the end of each treatment session. The most negative behaviour during entire treatment was considered.

\section{Statistical Analysis}

Statistical analyses were performed using SPSS version 22.0 (IBM Corporation, Armonk, NY, USA). Descriptive analysis was used to summarise demographic characteristics and responses of the participants on each scale. The chi-squared test was used to compare age and sex differences at baseline. Repeated-measures ANOVA was performed to analyse changes according to the treatment group, dental visit sequence, and time point of treatment procedure. Differences with $\mathrm{p}<0.05$ were considered to be statistically significant.

\section{Results}

Demographic information and baseline characteristics of the participants are summarised in Table 1. A total of 76 participants were enrolled, of which 70 were ultimately analysed. Six participants dropped out of the study due to personal and/or family reasons. Of the analysed participants, $54 \%(\mathrm{n}=38)$ were male, and the mean age was $8.97 \pm 1.39$ years. At baseline, there were no significant differences between the two groups in terms of characteristics and outcome measures. There was no significant difference between the groups in terms of treatment duration ( $\mathrm{p}>0.05$; One-way analysis of variance - ANOVA), which was $31.30 \pm 3.74 \mathrm{~min}$ (minimum, 23 min; maximum, $41 \mathrm{~min}$ ).

\section{Heart Rate Measurement for Dental Anxiety and Pain}

Table 2 presents the heart rate scores of participants according to group sequence, time points, and dental visit sequence. A two-way mixed ANOVA was performed to investigate the impact of dental visit sequence and time of treatment procedure on dental pain and anxiety according to the heart rate (Table 3). There was a significant main effect of dental visit sequence (Wilk's Lambda 0.856; F [1,68] = 11.398, p=0.001, $=0.144$ ), and also a main effect of time of treatment procedure (Wilk's Lambda $0.153, \mathrm{~F}[3,66]=121.985$, $\mathrm{p}=0.001,=0.847)$. While there was a significant interaction between dental visit sequence and treatment group $(\mathrm{p}=0.000)$, there was no significant interaction between the time of treatment procedure and the treatment 
group $(\mathrm{p}=0.236)$. While decreased dental anxiety and pain were associated with the first visit sequence with VR, there was no association between time points according to the group. There was no significant interaction between time of treatment procedure and dental visit sequence $(\mathrm{p}=0.273)$. There was also a significant interaction between dental visit sequence, time of treatment procedure, and treatment group $(\mathrm{p}=0.000)$, representing decreased dental pain and anxiety during local anaesthesia in VR group than in APC group, regardless of dental visit sequence. Further analysis of heart rate scores using repeated-measures revealed no significant differences between the groups and the other time of procedures $(\mathrm{p}>0.05)$.

Table 2. Mean (SD) heart rate scores of participants according to group sequence, time points, and dental visit sequence

\begin{tabular}{ccccc}
\hline Time Points & Group Sequence & \multicolumn{3}{c}{ Visit Period } \\
& & V1 & V2 & V1-V2 \\
\hline To & G1 (AB) & $83.75 \pm 7.36$ & $81.86 \pm 4.91$ & $1.88 \pm 7.13$ \\
& G2 (BA) & $85.85 \pm 7.08$ & $81.79 \pm 3.54$ & $4.05 \pm 7.88$ \\
T1 & G1 (AB) & $85.27 \pm 8.16$ & $84.41 \pm 7.50$ & $-.86 \pm 4.49$ \\
& G2 (BA) & $88.50 \pm 5.41$ & $87.26 \pm 5.95$ & $1.23 \pm 8.46$ \\
T2 & G1 (AB) & $105.63 \pm 12.39$ & $92.75 \pm 4.85$ & $1.88 \pm 11.24$ \\
& G2 (BA) & $96.64 \pm 6.30$ & $105.97 \pm 9.52$ & $-9.32 \pm 9.50$ \\
T3 & G1 (AB) & $87.72 \pm 6.05$ & $85.50 \pm 7.60$ & $1.22 \pm 8.07$ \\
& G2 (BA) & $87.14 \pm 5.08$ & $86.32 \pm 15.32$ & $.82 \pm 15.07$ \\
\hline
\end{tabular}

*Group A: Attention Placebo-Controlled; Group B: Virtual Reality; Vo: Baseline; V1: First Dental Treatment Visit; V2: Second Dental Treatment Visit; To: A Minute After Sitting in the Dental Unit; T1: Before Local Anaesthesia,; T2: During Local Anaesthesia; T3: End of the Treatment; SD: Standard Deviation.

Table 3. Assessment according to the heart rate: pairwise comparison between VR and APC.

\begin{tabular}{lccccccc}
\multicolumn{1}{c}{ Values } & \multicolumn{4}{c}{ Time Point } & \multicolumn{3}{c}{ Visit Sequence } \\
& To-T1 & To-T2 & To-T3 & T1-T2 & T1-T3 & T2-T3 & V1-V2 \\
\hline Mean Difference & -3.05 & -16.93 & -3.36 & -13.89 & 0.31 & 13.58 & 1.83 \\
Standard Error & 0.48 & 0.89 & 0.98 & 0.95 & 1.14 & 1.22 & 0.54 \\
p-value & 0.000 & 0.000 & 0.006 & 0.000 & 1.000 & 0.000 & 0.001 \\
\hline
\end{tabular}

*APC: Attention Placebo-Controlled; VR: Virtual Reality; V1: First Dental Treatment Visit; V2: Second Dental Treatment Visit; To: A Minute After Sitting in the Dental Unit; T1: Before Local Anaesthesia; T2: During Local Anaesthesia: T3: End of the Treatment.

\section{Self-Reported Dental Anxiety Measures}

Table 4 shows the dental anxiety scores on self-reported measurements and main effect of dental visit sequence. A one-way repeated-measures ANOVA was performed to investigate the impact of dental visit sequence on dental anxiety using self-reported measures, FIS, and CFSS-DS. Analysis of FIS scores revealed that there was a significant main effect of dental visit sequence (Wilk's Lambda 0.701, F[2,67] = 14.307, $\mathrm{p}=0.000,=0.299)$. There was no significant interaction between dental visit sequence and treatment group (Wilk's Lambda 0.927, F[2,67] = 2.631, p=0.079, = 0.073). Although, regardless of group, decreased dental anxiety and pain were associated with the baseline $(\mathrm{VO})$ and the other two visits, there was no association between FIS scores of the first (V1) and second visits (V2). The results of between-subject effect revealed no significant difference between the groups $(\mathrm{F}=0.596$, degrees of freedom $[\mathrm{df}]=1, \mathrm{p}=0.443)$.

Analysis of CFSS-DS scores revealed that there was a significant main effect of dental visit sequence (Wilk's Lambda 0.429, F[2,67] = 44.629, $\mathrm{p}=0.000,=0.571$ ). There was no significant interaction between dental visit sequence and treatment group (Wilk's Lambda 0.917, F $[2,67]=3.015, \mathrm{p}=0.056,=0.083$ ). Regardless of group, however, decreased dental anxiety and pain were associated with the baseline (Vo) and the other two visits, and there was no association between CFSS-DS scores of the first (V1) and second (V2) 
visits. The results of between-subject effect revealed no significant difference between the groups $(\mathrm{F}=3.187, \mathrm{df}$ $=1, \mathrm{p}=0.079)$.

Table 4. Dental anxiety scores on self-reported measurements and main effect of dental visit sequence.

\begin{tabular}{|c|c|c|c|c|c|c|c|c|c|c|}
\hline \multirow{3}{*}{ Visit } & \multirow{2}{*}{\multicolumn{2}{|c|}{$\begin{array}{l}\text { CFSS-DS Score } \\
\text { Group Sequence }\end{array}$}} & \multirow{2}{*}{\multicolumn{3}{|c|}{ Visit Effect }} & \multirow{2}{*}{\multicolumn{2}{|c|}{$\begin{array}{c}\text { FIS Score } \\
\text { Group Sequence }\end{array}$}} & \multicolumn{3}{|c|}{ Visit Effect } \\
\hline & & & & & & & & & & \\
\hline & G1 (AB) & G2 (BA) & $\mathrm{F}$ & p-value & $\eta^{2}$ & G1 (AB) & G2 (BA) & $\mathrm{F}$ & p-value & $\eta^{2}$ \\
\hline Vo & $37.38 \pm 4.78$ & $37.67 \pm 7.98$ & 44.629 & 0.000 & 0.571 & $3.36 \pm 1.24$ & $3.23 \pm 0.95$ & 14.307 & 0.000 & 0.299 \\
\hline $\mathrm{V}_{1}$ & $32.52 \pm 3.12$ & $28.79 \pm 3.20$ & & & & $2.86 \pm 1.15$ & $2.44 \pm 0.92$ & & & \\
\hline $\mathrm{V}_{2}$ & $29.94 \pm 9.12$ & $28.47 \pm 2.96$ & & & & $2.77 \pm 1.14$ & $2.82 \pm 1.16$ & & & \\
\hline
\end{tabular}

*Group A: Attention Placebo-Controlled; Group B: Virtual Reality; Vo: Baseline; V1: First Dental Treatment Visit; V2: Second Dental Treatment Visit.

\section{Self-Reported Dental Pain Measure}

Table 5 shows the dental pain scores on WBS and main effects of dental visit sequence and time points. A two-way mixed ANOVA was performed to investigate the impact of dental visit sequence and time of treatment procedure on dental pain using the WBS. There was a significant main effect of dental visit sequence (Wilk's Lambda 0.905, $\mathrm{F}[1,68]=7.160, \mathrm{p}=0.009$, $=0.095$ ), representing increased dental pain in the first visit irrespective of time points or group. There was also a significant main effect of time points (Wilk's Lambda $0.903, \mathrm{~F}[1,68]=7.341, \mathrm{p}=0.009,=0.097)$, representing an increased dental pain after local anaesthesia $(\mathrm{T} 2)$ rather than at the end of the treatment (T3), irrespective of the dental visit sequence or groups. However, further analysis of WBS scores using repeated-measures revealed no significant interactions either between time points and group $(\mathrm{p}=0.750)$, time points and visit sequence $(\mathrm{p}=0.958)$, or time points, visit sequence and groups $(\mathrm{p}=0.278)$.

Table 5. Dental pain scores on Wong-Baker Faces Pain Scale (WBS) and main effects of dental visit sequence and time points.

\begin{tabular}{|c|c|c|c|c|c|c|c|c|c|}
\hline \multirow{3}{*}{ Visit } & \multicolumn{3}{|c|}{ WBS Score } & \multicolumn{3}{|c|}{ Visit Effect } & \multicolumn{3}{|c|}{ Time Effect } \\
\hline & & roup Sequence & & & & & & & \\
\hline & Time & G1 (AB) & $\mathrm{G}^{2}(\mathrm{BA})$ & $\mathrm{F}$ & $\mathrm{p}$-value & $\eta^{2}$ & $\mathrm{~F}$ & $\mathrm{p}$-value & $\eta^{2}$ \\
\hline \multirow[t]{2}{*}{$\mathrm{V} 1$} & $\mathrm{~T} 2$ & $4.11 \pm 2.13$ & $3.52 \pm 1.65$ & 7.639 & 0.009 & 0.095 & 7.341 & 0.009 & 0.097 \\
\hline & Т3 & $3.30 \pm 1.87$ & $3.05 \pm 1.55$ & & & & & & \\
\hline \multirow[t]{2}{*}{$\mathrm{V} 2$} & $\mathrm{~T} 2$ & $4.00 \pm 1.85$ & $4.11 \pm 1.83$ & & & & & & \\
\hline & T3 & $3.38 \pm 1.57$ & $3.47 \pm 1.58$ & & & & & & \\
\hline
\end{tabular}

*V1: First Dental Treatment Visit; V2: Second Dental Treatment Visit; T2: During Local Anaesthesia: T3: End of the Treatment.

Dental Visit Behaviour Measure

A one-way repeated-measures ANOVA was performed to investigate the impact of dental visit sequence on dental visit behaviour. There was no significant main effect of dental visit sequence (Wilk's Lambda $0.940, \mathrm{~F}[2,67]=2.151, \mathrm{p}=0.0124)$. Further, there was no significant interaction between dental visit sequence and treatment group (Wilk's Lambda 0.930, $\mathrm{F}[2,67]=2.531$, $\mathrm{p}=0.08$ ). The Frankl Behaviour Scale scores did not differ between the groups $(\mathrm{p}=0.978)$.

\section{Discussion}

The first null hypothesis was rejected because VR was found to be effective in reducing dental anxiety and pain during local anaesthesia according to the heart rate scores. The second null hypothesis was rejected; it was of potential clinical importance because we observed a significant reduction in dental pain and anxiety as 
measured according to the heart rate, which favoured the standard objective vital sign. No significance was observed according to self-reported measurements. Findings of this study revealed that VR may be effective in reducing dental anxiety and pain in children during local anaesthesia. There was a decrease in dental pain and anxiety during local anaesthesia in the VR group compared with that in the APC group, regardless of dental visit sequence. This study also highlighted the presence of participatory bias in self-reported measures. Additionally, VR did not improve cooperation and dental visit behaviour in children.

To our knowledge, this was the first study to evaluate the effect of VR on dental anxiety and pain while also examining the Hawthorne effect by incorporating an APC group in the trial design. This design also enabled us to test whether there was a difference between the study outcomes evaluated using objective and subjective measurement tools. While there was no significant difference between the self-reported measure scores during the treatment session in both the groups, there was a significant difference with regard to the heart rate. Interestingly, there was a significant difference between the VR and APC groups in terms of the heart rate for both dental anxiety and pain, whereas there was no significant difference between the selfreported scales of the two groups. This can be explained by the Hawthorne effect, in which subjects respond more favourably when they are aware that they are being observed or that they are participating in an experiment [30]. Participants were able to provide more biased responses on self-reported scales, whereas there was no bias in objective assessments (heart rate). Heart rate is a direct measure of physiological action and shows changes in painful and stressful situations. As reported in previous studies, it can be used as an index for evaluating both anxiety and pain [29,33,34].

The main strength of the present study was its trial design. The randomised, within-subject, crossover, placebo-controlled design strengthened the validity of our findings. This study differed from the previous clinical studies that used a placebo-controlled group in that it demonstrated the Hawthorne effect. Although there was no distraction procedure in the APC group, the fact that the subjects were aware of their participation in the experiment may have led to a biased scoring on the self-reported scales, which enabled them to make their own assessments. The advantages of the cross-over design were that each patient acted as their own control, and that a relatively small sample size was required to compare parallel groups. The 2-week period between the two sessions was found to be adequate and consistent with the literature [26]. This 2-week period was sufficient because the patients had the opportunity to renew their memory related to the previous session while also being short enough so as to not allow the deterioration of oral health and caries. Furthermore, there was no possibility of systemic residual effect of VR. Unlike drug trials, there were no additional reservations about possible adverse treatment interactions. However, the sample size was adequate, and the experiment did not lack statistical power, mainly due to the use of a cross-over design. The rate of withdrawal from the study was considerably lower than expected, which may be due to the fact that VR devices are of interest to both children and parents.

Each treatment session lasted for as short as $30 \mathrm{~min}$, which prevented the participants from wearing the devices for a prolonged period. This treatment duration is consistent with that in previous studies [26,29,37]. School-age children (7-11 years) were included in this study. This is because pre-school age groups exhibit higher levels of fear and anxiety than school-age children, suggesting that pre-school children are not physically and cognitively suitable for VR [38]. Moreover, distraction has been shown to be more effective in older age groups [19]. Another reason for selecting school-age children was that younger age groups exhibit more incompatible and uncontrollable behaviour in the dental unit [29,39,40]. This study was performed in a university clinic, which may affect the clinical environment. All patients were treated in a single room to 
eliminate this limitation. Using cotton rolls was found to be acceptable and comfortable by both patients and the operator.

Previous studies have confirmed the efficacy of VR or audiovisual distraction using video eyeglasses in reducing dental anxiety and pain in children [6,7,12,13,21,29,38]. Similarly, the results of this study revealed that although VR was effective in reducing dental anxiety and pain during local anaesthesia with regard to the heart rate, there was no difference among other the treatment time points. This can be explained by the nature of dental treatment protocol, in which local anaesthesia is the most painful and stressful procedure [34]. Conversely, it has been reported that audiovisual distraction reduced heart rate scores during the use of a hand piece [41]. A previous study also concluded no difference in distress during all treatment procedures between patients wearing and not wearing video eyeglasses during local anaesthesia [26].

Frankl Behaviour Scale scores did not differ according to the treatment group or dental visit sequence. This finding is consistent with those of the previous studies that did not reveal any behavioural differences after the use of audiovisual distraction $[37,42]$. This may be because patients were given the opportunity to watch preferred content, which enabled them to have positive perceptions and acceptability of VR [37,43]. This also compensated for the lack of kinaesthetic elements of VR [26,37]. Another explanation may be the exclusion of extremely uncooperative patients during sample selection. Contrastingly, it has been reported that using video eyeglasses in the first session precludes communication with the child and leads to non-cooperation [27]. This difference may be explained by sample characteristics, in which healthy patients were included in the present investigation, while special-needs children were included in the previous study.

This study had several limitations. A major limitation was the routine use of distraction glasses instead of the VR headset in the APC group. This was because in the pilot study, an attempt to control bias was made by permitting the subjects to wear the VR headset without playing any movies. However, most children refused to wear the VR headset without a movie during treatment. This may be due to the fact that those with high trait anxiety are unable to tolerate this type of distraction. Similarly, patients who want to focus on the treatment procedure present with high anxiety because they feel a lack of control due to the presence of the VR device [44]. Another limitation was the relatively small sample size. However, the crossover design of the study, the considerably low drop-out rate during the study, and the high statistical power in determining the sample size mitigated this limitation. Additionally, participants applied to a single treatment centre and were selected by convenience sampling. Many environmental factors that could have an impact on the participants' dental anxiety and pain were ignored. Future research should be conducted in different centres and with larger sample sizes; as such, the validity of the findings should be supported. One more limitation was that participants themselves selected the audiovisual material used. Some previous studies have emphasised the importance of permitting participants to choose audiovisual materials themselves, and the way this affects their behaviour [7,8,29]. Conversely, when children are allowed to choose the audiovisual material, they feel more comfortable tolerating the VR device for a longer duration; also, they can have control, which reduces stress levels. Normally, children have very limited control over their surroundings in clinical dental settings; therefore, it may be beneficial for them to have control over the content being viewed. In addition, the order in which the content is monitored during treatment sessions is also important. Future studies should examine whether there are any differences depending on the content of the audiovisual material and the order in which it is displayed.

\section{Conclusion}


Virtual reality significantly reduced pain and anxiety during local anaesthesia in children undergoing dental treatment; therefore, it may be recommended during dental treatment in school-age children. This study also highlighted the presence of participatory bias in the self-reported measures, confirmed by the difference between objective and subjective outcome measures.

\section{Authors' Contributions}

BB (D) https://orcid.org/0000-0003-4764-819X Conceptualization, Methodology, Investigation, Formal Analysis, Writing - Original Draft Preparation and Writing - Review and Editing.

MC (D) https://orcid.org/0000-0002-9839-871X Conceptualization, Methodology, Investigation, Writing - Original Draft Preparation and Writing - Review and Editing.

All authors declare that they contributed to critical review of intellectual content and approval of the final version to be published.

\section{Financial Support}

This work was funded by the Scientific Research Project Fund of Sivas Cumhuriyet University under the grant number DIS-2 17.

\section{Conflict of Interest}

The authors declare no conflicts of interest.

\section{Data Availability}

The data used to support the findings of this study can be made available upon request to the corresponding author.

\section{References}

[1] Buldur B, Armfield J. Development of the Turkish version of the Index of Dental Anxiety and Fear (IDAF-4C+): Dental anxiety and concomitant factors in pediatric dental patients. J Clin Pediatr Dent 2018; 42(4):279-86. https://doi.org/10.17796/1053-4628-42.4.7

[2] Morgan AG, Rodd HD, Porritt JM, Baker SR, Creswell C, Newton T, et al. Children's experiences of dental anxiety. Int J Paediatr Dent 2017; 27(2):87-97. https://doi.org/10.1111/ipd.12238.

[3] Shim Y-S, Kim A-H, Jeon E-Y, An S-Y. Dental fear \& anxiety and dental pain in children and adolescents: a systemic review. J Dent Anesth Pain Med 2015; 15(2):53-61. https://doi.org/10.17245/jdapm.2015.15.2.53

[4] Gujjar KR, van Wijk A, Kumar R, de Jongh A. Efficacy of virtual reality exposure therapy for the treatment of dental phobia in adults: A randomized controlled trial. J Anxiety Disord 2019; 62(1):100-8. https://doi.org/10.1016/j.janxdis.2018.12.001

[5] Buldur B. Pathways between parental and individual determinants of dental caries and dental visit behaviours among children: Validation of a new conceptual model. Community Dent Oral Epidemiol 2020; 48(4):280-7. https://doi.org/10.1111/cdoe.12530

[6] Lin C-S, Wu S-Y, Yi C-A. Association between anxiety and pain in dental treatment: a systematic review and metaanalysis. J Dent Res 2017; 96(2):153-62. https://doi.org/10.1177/0022034516678168

[7] Liu Y, Gu Z, Wang Y, Wu Q, Chen V, Xu X, Zhou X. Effect of audiovisual distraction on the management of dental anxiety in children: a systematic review. Int J Paediatr Dent 2019; 29(1):14-21. https://doi.org/10.1111/ipd.12430

[8] Prado IM, Carcavalli L, Abreu LG, Serra-Negra JM, Paiva SM, Martins CC. Use of distraction techniques for the management of anxiety and fear in paediatric dental practice: a systematic review of randomized controlled trials. Int J Paediatr Dent 2019; 29(5):650-68. https://doi.org/10.1111/ipd.12499

[9] Achmad MH, Horax S, Rizki SS, Ramadhany S, Singgih MF, Handayani H, et al. Pulse rate change after childhood anxiety management with modeling and reinforcement technique of children's dental care. Pesqui Bras Odontopediatria Clin Integr 2019; 19:e4655. https://doi.org/10.4034/PBOCI.2019.191.97

[10] Bradt J, Teague A. Music interventions for dental anxiety. Oral Dis 2018; 24(3):300-6. https://doi.org/10.1111/odi.12615

[11] Nuvvula S, Alahari S, Kamatham R, Challa R. Effect of audiovisual distraction with 3D video glasses on dental anxiety of children experiencing administration of local analgesia: a randomised clinical trial. Eur Arch Paediatr Dent 2015; 16(1):43-50. https://doi.org/10.1007/s40368-014-0145-9

[12] Zhang C, Qin D, Shen L, Ji P, Wang J. Does audiovisual distraction reduce dental anxiety in children under local anesthesia? a systematic review and meta-analysis. Oral Dis 2019; 25(2):416-24. doi: 10.1111/odi.12849.

[13] Ram D, Shapira J, Holan G, Magora F, Cohen S, Davidovich E. Audiovisual video eyeglass distraction during dental treatment in children. Quintessence Int 2010; 41(8):673-9. 
[14] Botella C, Fernández-Álvarez J, Guillén V, García-Palacios A, Baños R. Recent progress in virtual reality exposure therapy for phobias: a systematic review. Curr Psychiatry Rep 2017; 19(7):42-9.

https://doi.org/10.1007/s11920-017-0788-4

[15] Carl E, Stein AT, Levihn-Coon A, Pogue JR, Rothbaum B, Emmelkamp P, et al. Virtual reality exposure therapy for anxiety and related disorders: a meta-analysis of randomized controlled trials. J Anxiety Disord 2019; 61:27-36. https://doi.org/10.1016/j.janxdis.2018.08.003

[16] Krijn M, Emmelkamp PM, Olafsson RP, Biemond R. Virtual reality exposure therapy of anxiety disorders: a review. Clin Psychol Rev 2004; 24(3):259-81. https://doi.org/10.1016/j.cpr.2004.04.001

[17] Aminabadi NA, Erfanparast L, Sohrabi A, Oskouei SG, Naghili A. The impact of virtual reality distraction on pain and anxiety during dental treatment in 4-6 year-old children: a randomized controlled clinical trial. J Dent Res Dent Clin Dent Prospects 2012; 6(4):117-24. https://doi.org/10.5681/joddd.2012.025

[18] El-Sharkawi HF, El-Housseiny AA, Aly AM. Effectiveness of new distraction technique on pain associated with injection of local anesthesia for children. Pediatr Dent 2012; 34(2):35-8.

[19] Gujjar KR, Sharma R, Jongh AD. Virtual reality exposure therapy for treatment of dental phobia. Dent Update 2017; 44(5):423-35. https://doi.org/10.12968/denu.2017.44.5.423

[20] Hoge MA, Howard MR, Wallace DP, Allen KD. Use of video eyewear to manage distress in children during restorative dental treatment. Pediatr Dent 2012; 34(5):378-82.

[21] Raghav K, Van Wijk A, Abdullah F, Islam MN, Bernatchez M, De Jongh A. Efficacy of virtual reality exposure therapy for treatment of dental phobia: a randomized control trial. BMC Oral Health 2016; 16(1):25-35. https://doi.org/10.1186/s12903-016-0186-z

[22] Baus O, Bouchard S. Moving from virtual reality exposure-based therapy to augmented reality exposure-based therapy: a review. Front Hum Neurosci 2014; 8:1 12-26. https://doi.org/10.3389/fnhum.2014.00112

[23] Costa RTd, Carvalho MRd, Nardi AE. Virtual reality exposure therapy in the treatment of driving phobia. PsicTeor e Pesq 2010; 26(1):131-7. https://doi.org/10.1590/So102-37722010000100015

[24] Shahnavaz S, Hedman E, Grindefjord M, Reuterskiöld L, Dahllöf G. Cognitive behavioral therapy for children with dental anxiety: a randomized controlled trial. JDR Clin Trans Res 2016; 1(3):234-43. https://doi.org/10.1177/2380084416661473

[25] Gujjar KR, van Wijk A, Sharma R, de Jongh A. Virtual reality exposure therapy for the treatment of dental phobia: a controlled feasibility study. Behav Cogn Psychother 2018; 46(3):367-73. https://doi.org/10.1017/S1352465817000534

[26] Al-Khotani A, Bello LAa, Christidis N. Effects of audiovisual distraction on children's behaviour during dental treatment: a randomized controlled clinical trial. Acta Odontol Scand 2016; 74(6):494-501. https://doi.org/10.1080/00016357.2016.1206211

[27] Bagattoni S, D'alessandro G, Sadotti A, Alkhamis N, Piana G. Effects of audiovisual distraction in children with special healthcare needs during dental restorations: a randomized crossover clinical trial. Int J Paediatr Dent 2018; 28(1):111-20. https://doi.org/10.1111/ipd.12304

[28] Gujjar KR, Van Wijk A, Kumar R, De Jongh A. Are technology-based interventions effective in reducing dental anxiety in children and adults? a systematic review. J Evid Based Dent Pract 2019; 19(2):140-55.

[29] Jimeno FG, Bellido MM, Fernández CC, Rodríguez AL, Pérez JL, Quesada JB. Effect of audiovisual distraction on children's behaviour, anxiety and pain in the dental setting. Eur J Paediatr Dent 2014; 15(3):297-302.

[30] McCarney R, Warner J, Iliffe S, Van Haselen R, Griffin M, Fisher P. The Hawthorne effect: a randomised, controlled trial. BMC Med Res Methodol 2007; 7(1):30-7. https://doi.org/10.1186/1471-2288-7-30

[31] Popp L, Schneider S. Attention placebo control in randomized controlled trials of psychosocial interventions: theory and practice. Trials 2015; 16(1):150-52. https://doi.org/10.1186/s13063-015-0679-0

[32] Frankl S. Should the parent remain with the child in the dental operatory? J Dent Child 1962; 29:150-63.

[33] Jimeno FG, Bielsa SY, Fernández CC, Rodríguez AL, Bellido MM. Objective and subjective measures for assessing anxiety in paediatric dental patients. Eur J Paediatr Dent 2011;12(4):239-44.

[34] Hegde KM, Srinivasan I, Melwani A, Radhakrishna S. Effect of vibration during local anesthesia administration on pain, anxiety, and behavior of pediatric patients aged 6-11 years: a crossover split-mouth study. J Dent Anesth Pain Med 2019; 19(3):143-9. https://doi.org/10.17245/jdapm.2019.19.3.143

[35] Kuscu O, Caglar E, Kayabasoglu N, Sandalli N. Preferences of dentist's attire in a group of Istanbul school children related with dental anxiety. Eur Arch Paediatr Dent 2009; 10(1):38-41.

[36] Buchanan H, Niven N. Validation of a Facial Image Scale to assess child dental anxiety. Int J Paediatr Dent 2002; $12(1): 47-52$.

[37] Attar R, Baghdadi Z. Comparative efficacy of active and passive distraction during restorative treatment in children using an iPad versus audiovisual eyeglasses: a randomised controlled trial. Eur Arch Paediatr Dent 2015; 16(1):1-8. https://doi.org/10.1007/s40368-014-0136-x

[38] Prabhakar A, Marwah N, Raju O. A comparison between audio and audiovisual distraction techniques in managing anxious pediatric dental patients. J Indian Soc Pedo Prev Dent 2007; 25(4):177-82.

https://doi.org/10.4103/0970-4388.37014 
[39] Buldur B. Angel or devil? Dentists and dental students conceptions of pediatric dental patients through metaphor analysis. J Clin Pediatr Dent 2018; 42(2):1 19-24. https://doi.org/10.17796/1053-4628-42.2.7

[40] Buldur B. Behavior management in pediatric dentistry: an overview and interpretation. Pesqui Bras Odontopediatria Clin Integr 2019; 19(1):e4649. https://doi.org/10.4034/PBOCI.2019.191.ed 1

[41] Mitrakul K, Asvanund Y, Arunakul M, Paka-Akekaphat S. Effect of audiovisual eyeglasses during dental treatment in 5-8 year-old children. Eur J Paediatr Dent 2015; 16(3):239-45. https://doi.org/10.1177/0022034516678168

[42] Aitken JC, Wilson S, Coury D, Moursi AM. The effect of music distraction on pain, anxiety and behavior in pediatric dental patients. Pediatr Dent 2002; 24(2):114-8.

[43] Filcheck HA, Allen KD, Ogren H, Darby JB, Holstein B, Hupp S. The use of choice-based distraction to decrease the distress of children at the dentist. Child Fam Behav Ther 2005; 26(4):59-68. https://doi.org/10.1300/Jo19v26n04_04

[44] Sharar SR, Carrougher GJ, Nakamura D, Hoffman HG, Blough DK, Patterson DR. Factors influencing the efficacy of virtual reality distraction analgesia during postburn physical therapy: preliminary results from 3 ongoing studies. Arch Phys Med Rehabil 2007; 88(12 Suppl 2):S43-9. https://doi.org/10.1016/j.apmr.2007.09.004 